\title{
Experimental Investigation of Direct Contact Baseplate Cooling for Electric Vehicle Power Electronics
}

\author{
Jasper Nonneman ${ }^{1,3}$, Stephan Schlimpert ${ }^{3}$, Ilya T'Jollyn ${ }^{1,3}$, Peter Sergeant ${ }^{2,3}$, Michel De Paepe ${ }^{1,3}$ \\ ${ }^{1}$ Department of Flow, Heat and Combustion Mechanics, Ghent University, Sint-Pietersnieuwstraat 41, 9000 Ghent, Belgium \\ ${ }^{2}$ Department of Electrical Energy, Metals, Mechanical Constructions and Systems, Ghent University, 9052 Ghent, Belgium \\ ${ }^{3}$ Flanders Make, Core Lab MotionS, Gaston Geenslaan 8, 3001, Leuven, Belgium
}

Email: Jasper.Nonneman@UGent.be

\begin{abstract}
An experimental setup has been built to investigate the thermo-hydraulic performance of the direct contact baseplate cooling technique for power electronics in electric vehicles, to improve the design and to validate the modelling of this technique. The setup consists of an electrical heater to emulate the heat dissipation of the power electronics and which is cooled by a $60 / 40 \%$ mixture by mass of water-glycol. It is equipped with a flow rate sensor, absolute and differential pressure sensors and temperature measurements at the inlet, outlet and baseplate over the channel length, to determine the performance parameters used in the comparison: thermal resistance and pumping power. Three fluid inlet temperatures, four power levels and four flow rates have been tested for three channel heights $(1.5 \mathrm{~mm}, 3 \mathrm{~mm}$ and $7.6 \mathrm{~mm})$. Increasing the fluid temperature and/or heating power, results in a lower thermal resistance and pumping power, due to a lower viscosity of the fluid. The performance of the $1.5 \mathrm{~mm}$ and $7.6 \mathrm{~mm}$ channel was found to be quite similar, while the $3 \mathrm{~mm}$ channel results on average in a $5.8 \%$ lower thermal resistance compared to the other two channel heights. The heat transfer in terms of the Nusselt number was also evaluated in function of the Reynolds number. By analyzing the hydraulic and thermal entrance lengths it could be concluded that the flow in all measurements is simultaneously developing. A comparison with two correlations from scientific literature for simultaneously developing flow did not show a good agreement, possibly due to the specific inlet and outlet effect, which is more pronounced for a bigger channel height than a smaller channel height.
\end{abstract}

KEY WORDS: Inverter cooling, Experimental investigation, Direct contact baseplate cooling, Developing flow, Inlet effect, Thermal resistance, Pumping power

$\begin{array}{ll}\text { NOMENCLATURE } \\ \boldsymbol{A} & \text { Area }\left(\mathrm{m}^{2}\right) \\ \boldsymbol{C} & \text { Constant } \\ \boldsymbol{c}_{\boldsymbol{p}} & \text { Specific heat }(\mathrm{J} / \mathrm{kgK}) \\ \boldsymbol{D}_{\boldsymbol{h}} & \text { Hydraulic diameter }(\mathrm{m}) \\ \boldsymbol{f} & \text { Friction factor } \\ \boldsymbol{g} & \text { Gravitational acceleration }\left(\mathrm{m} / \mathrm{s}^{2}\right) \\ \boldsymbol{h} & \text { Channel height }(\mathrm{m}) \\ \boldsymbol{I} & \text { Current }(\mathrm{A}) \\ \boldsymbol{k} & \text { Thermal conductivity }(\mathrm{W} / \mathrm{mK}) \\ \boldsymbol{L} & \text { Length }(\mathrm{m}) \\ \boldsymbol{N} \boldsymbol{u} & \text { Nusselt number } \\ \boldsymbol{p} & \text { Pressure }(\text { Pa) } \\ \boldsymbol{P}_{\boldsymbol{p}} & \text { Pumping power }(\mathrm{W}) \\ \boldsymbol{P r} & \text { Prandtl number } \\ & \end{array}$

$\begin{array}{ll}\boldsymbol{Q} & \text { Heat }(\mathrm{W}) \\ \boldsymbol{R} & \text { Thermal resistance }(\mathrm{K} / \mathrm{W}) \\ \boldsymbol{R} \boldsymbol{e} & \text { Reynolds number } \\ \boldsymbol{T} & \text { Temperature }\left({ }^{\circ} \mathrm{C}\right) \\ \boldsymbol{V} & \text { Voltage }(\mathrm{V}) \\ \dot{\boldsymbol{V}} & \text { Flow rate }\left(\mathrm{m}^{3} / \mathrm{s}\right) \\ \boldsymbol{v} & \text { Velocity }(\mathrm{m} / \mathrm{s}) \\ \boldsymbol{w} & \text { Width }(\mathrm{m}) \\ \boldsymbol{x} & \text { Distance }(\mathrm{m})\end{array}$

$\begin{array}{ll}\text { Greek symbols } \\ \boldsymbol{\delta} & \text { Uncertainty } \\ \boldsymbol{\Delta} & \text { Difference } \\ \boldsymbol{\mu} & \text { Dynamic viscosity }(\mathrm{Pa} . \mathrm{s}) \\ \boldsymbol{v} & \text { Kinematic viscosity }\left(\mathrm{m}^{2} / \mathrm{s}\right) \\ \boldsymbol{\rho} & \text { Density }\left(\mathrm{kg} / \mathrm{m}^{3}\right) \\ \boldsymbol{\sigma}_{\boldsymbol{x}} & \text { Standard deviation }\end{array}$

$\begin{array}{ll}\text { Subscripts } \\ \text { abs } & \text { absolute } \\ \text { Al } & \text { aluminum } \\ \text { avg } & \text { average } \\ b & \text { bulk } \\ e & \text { electric } \\ f & \text { fluid, flow } \\ h & \text { hydraulic } \\ \text { ht } & \text { heat transfer } \\ \text { in } & \text { inlet } \\ \text { lam } & \text { laminar } \\ \text { meas } & \text { measured } \\ \text { out } & \text { outlet } \\ \text { rand } & \text { random } \\ \text { sys } & \text { systematic } \\ \text { TC } & \text { thermocouple } \\ \text { th } & \text { thermal } \\ \text { turb } & \text { turbulent } \\ w & \text { wall }\end{array}$

\section{INTRODUCTION}

Electric vehicles are becoming an important part of the automotive market and their share is growing. The drivetrain of these vehicles uses power electronics to convert the energy from batteries to a suitable voltage and frequency for the electric motor [1]. The power density of these drivetrains is ever increasing, which also results in higher heat fluxes in the power electronics [2].

In [3], several cooling methods suitable for the cooling of the power electronics in electric vehicles were investigated, such as forced convective cooled heat sinks with air (with and 
without integrated heat pipes), liquid cooled cold plates, direct contact baseplate cooling and liquid cooled baseplates with integrated pin fins. From a certain power density, conventional cooling methods such as air cooling and cold plates cannot deliver the necessary cooling rate anymore [2]. Direct contact baseplate cooling shows a great potential, because of the simple and robust design. Further, no modifications on the convectional baseplate geometry are necessary [3]. A possible drawback of this method is the non-uniform temperature at the baseplate, due to the developing flow effect in the channel and the gradient in the fluid temperature [3] [4].

An example on how this cooling method can be applied, is shown in Figure 1. Within a cooling block, a channel, inlet and outlet are milled. Onto this block, the power electronic baseplate is attached with a sealing in between, allowing a fluid to flow over the baseplate in a sealed enclosure.

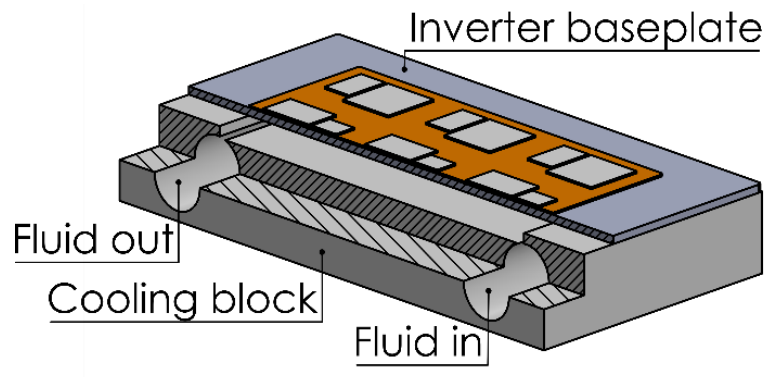

Figure 1:Direct contact baseplate cooling: a possible implementation

Several studies were found in literature on the experimental investigation of pin fins integrated in the baseplate [4] [5] and turbulators situated in a similar channel between the baseplate and cooling block as shown in Figure 1. These turbulator concepts include for example the 'Shower-Power' [4] and high shear direct contact (HSDC) cooling [6]. However, until the writing of this paper, no specific experimental investigation was carried out on the direct contact baseplate cooling as described in this paper, without any turbulators in the channel.

For this reason and in the framework of the ICON Hipercool project, an experimental setup was designed and built to investigate the direct contact baseplate cooling experimentally, similar to [7]. To be able to measure the power dissipation accurately and to make the measurements less complex, an electrical heater is used in the setup to emulate the power electronics, so no real power electronic modules are used in this study. The objective of this paper is to characterize the direct contact baseplate cooling of power electronics thermohydraulically, based on experiments with different heating powers, inlet temperatures of the fluid, and channel heights.

\section{EXPERIMENTAL SETUP}

\section{Overview}

The experimental liquid cooling setup is designed such that different drive train components (power electronics; motor tooth; DC-DC charger; etc.) can be experimentally investigated in a fast, efficient and accurate manner due to a plug and play design with respect to the test section. The setup consists of a fluid conditioning part and a test section, an overview is shown in Figure 2. From a reservoir filled with a $60 / 40 \%$ by mass mixture of water-glycol, a gear pump pumps the fluid to the test section. After the test section, the fluid is conditioned to the desired temperature and flows back into the reservoir. An additional oil circuit has been analogously designed to investigate the effect of the chosen fluid on the thermal performance. Within this paper the results with respect to the water-glycol cooling are presented. The ambient temperature in the lab is controlled by an HVAC system, depending on the temperature level of the fluid to avoid heat losses from the test section to the ambient.

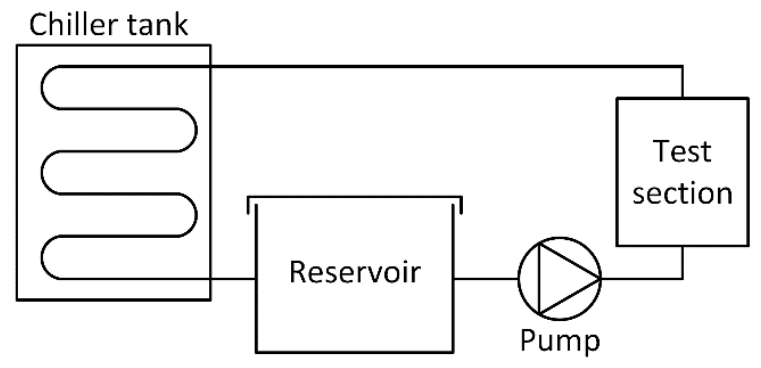

Figure 2: Overview of the experimental setup.

\section{Test section}

An overview of the test section is shown in Figure 3 and a more detailed sectional drawing in Figure 4. It consists of a $45 \mathrm{~mm}$ thick channel block made from POM, in which a rectangular fluid channel, inlet, outlet and connections between the aforementioned are milled. An aluminum flat baseplate of $5 \mathrm{~mm}$ thick is mounted on top of this block, resulting in a closed channel between the baseplate and the channel block. This places the fluid in direct contact with the bottom of the baseplate. The channel between the two components is sealed by a rubber sealing which is located in a milled groove in the cooling block.

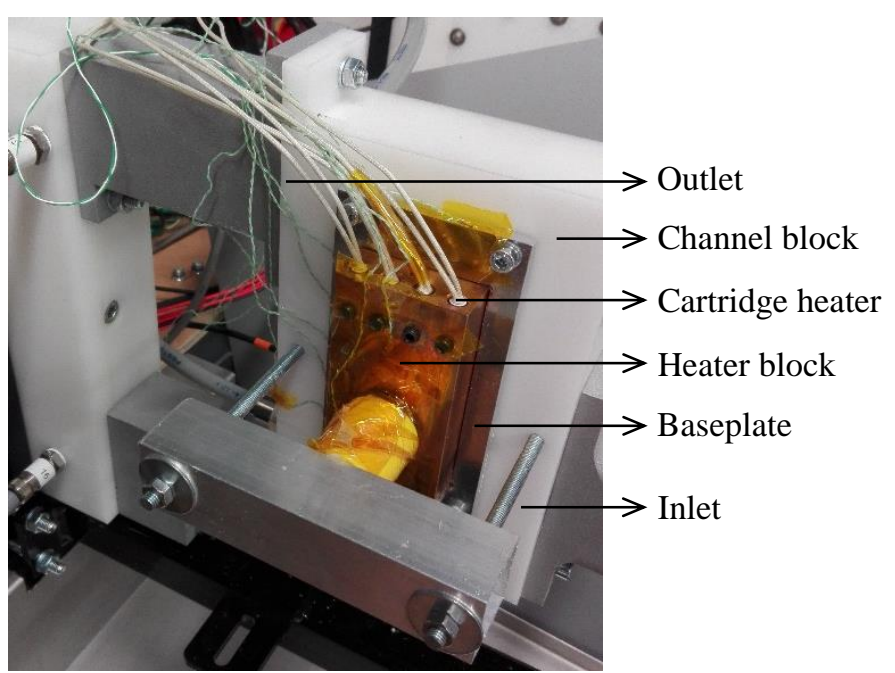

Figure 3: Overview of the test section (insulation not shown).

A copper heater block (50x108mm and 20mm thick) with four integrated cartridge heaters is pressed against the other side of the baseplate into a recess of $1 \mathrm{~mm}$ deep. The circular cartridge heaters $(\varnothing 6.5 \times 108 \mathrm{~mm})$ each with a maximum power of $400 \mathrm{~W}$, are uniformly distributed over the heater block and the centers are located at a distance of $13.5 \mathrm{~mm}$ from the bottom of the heater block. The dissipated heat in the cartridge heaters is conducted through the copper heater block to the top surface of the baseplate. A copper foil of $0.15 \mathrm{~mm}$ is applied between the heater block and baseplate, to improve the thermal contact. 
The heat is further conducted through the baseplate, to the side which is in contact with the fluid $(50 \times 108 \mathrm{~mm})$ and where it is transferred to the fluid by convection.

No other heat paths from heater to fluid than the one by convection from baseplate surface to fluid are desired. Therefore, a 50mm thick layer of PUR insulation is put on top of the heater to avoid heat losses to the environment. Further, to limit the heat going to the fluid by conduction through the channel block, it is constructed from POM, which is a material with a low thermal conductivity $(0.24 \mathrm{~W} / \mathrm{mK})$.

The fluid channel has a rectangular shape and is mounted in vertical direction so that the fluid flows from bottom to top. It is $108 \mathrm{~mm}$ long in the direction of the fluid flow, $50 \mathrm{~mm}$ wide and the height is variable. The fluid enters the test section at the inlet $(\varnothing 20 \times 50 \mathrm{~mm})$ perpendicular to the sectional view, as indicated with the symbol $\otimes$ in Figure 4 . Then it is deflected $90^{\circ}$ from the $\otimes$-direction to the $-\mathrm{x}$-direction and passes through a short passage of $4 \mathrm{~mm}$ wide and $3.5 \mathrm{~mm}$ long after which it is deflected again in the $y$-direction of the channel, as indicated by the arrows. At the end of the channel, the flow is deflected $90^{\circ}$ to the $\mathrm{x}$-direction and passes through a short passage with the same dimensions as the previous one. Finally, the flow is again deflected in the direction perpendicular of the sectional view, as indicated by the symbol $\otimes$ and leaves the test section by the outlet (Ø20x50mm). With this design, the fluid can be assumed to be uniformly distributed over the fluid channel.

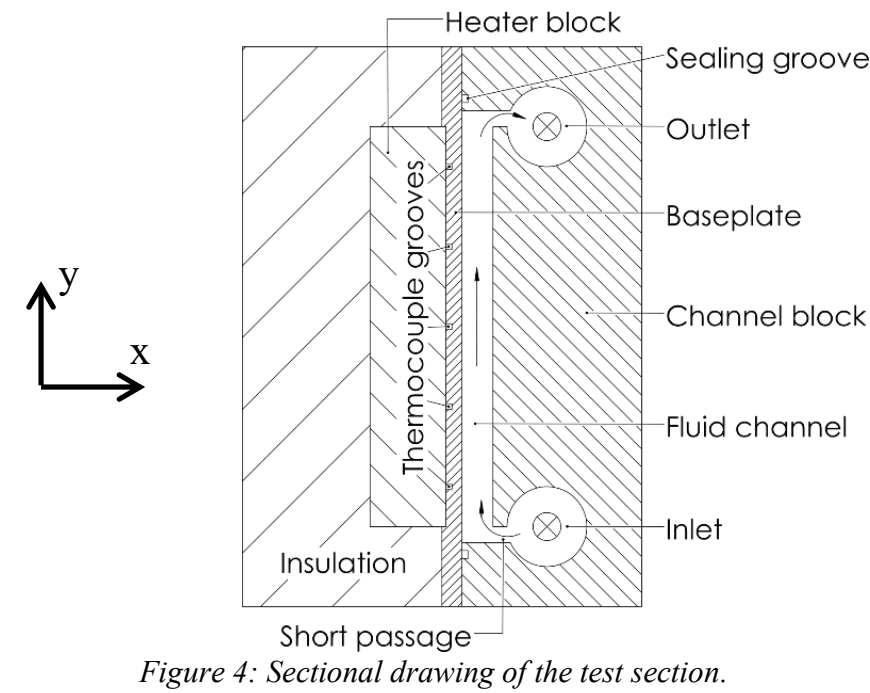

Other variations of the heat sink design (pin fin, turbulator, cold plate) and with respect to a real power electronic module as evident in inverters will be investigated with this setup in a separate publication.

\section{Sensors}

To characterize the heat transfer performance of the cooling method, several sensors are placed in and around the test section. The fluid temperatures before and after the test section are measured with a probe type PT100 class A. To allow for a discrete measurement of the baseplate wall temperature along the fluid direction, five grooves were milled in the recess of the baseplate (at the top side), uniformly distributed over the flow direction. The grooves are $1.5 \times 1.5 \mathrm{~mm}$ and run from the side of the baseplate until the middle of the channel. At the end of each groove a K-type thermocouple is placed, embedded in thermal paste $(4 \mathrm{~W} / \mathrm{mK})$ to avoid remains of air in the grooves from disturbing the temperature profile. Further, some additional temperature sensors were positioned on the heater block and baseplate for safety measures and proper operation of the setup.

The pressure drop over the test section is determined with a differential pressure transmitter and the absolute pressure is measured at the inlet section with a piezoresistive strain gauge pressure transducer. The volumetric flow rate through the test section is measured with an ultrasonic flow meter. The electrical power supplied to the cartridge heaters is determined by measuring the current and voltage. The current is measured with a closed loop hall effect transducer and the voltage with a DC voltage transducer. A summary of the used sensors, ranges and accuracies is shown in Table 1 .

Table 1: Range and uncertainty of the used measurement sensors.

\begin{tabular}{|l|c|c|}
\hline Sensor & Range & Uncertainty \\
\hline PT100 & $-50 \ldots 120^{\circ} \mathrm{C}$ & $\pm 0.15^{\circ} \mathrm{C}$ \\
\hline K-type thermocouple & $-50 \ldots 250^{\circ} \mathrm{C}$ & $\pm 1^{\circ} \mathrm{C}$ \\
\hline Differential pressure & $0 \ldots 0.2 \mathrm{bar}$ & $\pm 0.001 \mathrm{bar}$ \\
\hline Absolute pressure & $0 \ldots 4 \mathrm{bar}$ & $\pm 0.02 \mathrm{bar}$ \\
\hline Ultrasonic flow meter & $0.3 \ldots 21 \mathrm{l} / \mathrm{min}$ & $\pm 1 \%$ \\
$\pm 0.0141 / \mathrm{min}$ \\
\hline Current & $0 \ldots 75 \mathrm{~A}$ & $\pm 1 \%$ \\
\hline $\begin{array}{l}\text { Voltage } \\
\text { Pressure tap vertical }\end{array}$ & $0 \ldots 200 \mathrm{~V}$ & $\pm 1 \%$ \\
\hline
\end{tabular}

\section{Measurement plan and procedure}

To evaluate the direct contact baseplate cooling technique experimentally, three different channel heights are investigated: $1.5 \mathrm{~mm}, 3 \mathrm{~mm}$ and $7.6 \mathrm{~mm}$. Further, also three different inlet temperatures are used: $20^{\circ} \mathrm{C}, 35^{\circ} \mathrm{C}$ and $50^{\circ} \mathrm{C}$, which are common values that occur in electric vehicles. For each combination of the aforementioned, the heating power is varied on 4 levels from $100-640 \mathrm{~W}$ and the flow rate is varied on 4 levels from $6-121 / \mathrm{min}$ in the $1.5 \mathrm{~mm}$ case and from $9-171 / \mathrm{min}$ in the $3 \mathrm{~mm}$ and $7.6 \mathrm{~mm}$ cases. An overview of the tests and combinations is shown in Table 2.

Table 2: Overview of the measurements.
\begin{tabular}{|l|c|c|c|}
\hline $\boldsymbol{h}(\mathrm{mm})$ & $\mathbf{1 . 5}$ & $\mathbf{3}$ & $\mathbf{7 . 6}$ \\
\hline $\boldsymbol{T}_{\boldsymbol{i n}}\left({ }^{\circ} \mathrm{C}\right)$ & $20,35,50$ & $20,35,50$ & 20,50 \\
\hline $\boldsymbol{Q}(\mathrm{W})$ & \multicolumn{3}{|c|}{$100,288,468$ and 640} \\
\hline$\dot{\boldsymbol{V}}_{\boldsymbol{f}}(1 / \mathrm{min})$ & $5,8,10$ and 12 & $9,11.7,14.3$ and 17 \\
\hline
\end{tabular}

At the start of a test, the appropriate channel height was set. For each of the different heights, a different channel block was manufactured, so the channel blocks had to be replaced when another height was tested. Next, a certain fluid inlet temperature was set, along with the corresponding lab temperature $\left(T_{a m b}=\right.$ $20^{\circ} \mathrm{C}$ for $T_{i n}=20^{\circ} \mathrm{C} ; T_{a m b}=28^{\circ} \mathrm{C}$ for $T_{i n}=35$ and $\left.50^{\circ} \mathrm{C}\right)$. As a consequence of the high thermal inertia of the chiller tank and reservoir, the setup first ran for $4 \mathrm{~h}$ at the highest flow rate without heating power. After this period, the temperature in the chiller tank and fluid in the setup was stable and the tests could start. The tests were done in the order of decreasing flow rate and at every flow rate, all heating power levels were tested in increasing order. One stable setpoint was measured for a period of $10 \mathrm{~min}$ to attain the steady-state values. Between every other 
power level setpoint, there was a stabilization time of 30min, which was enough due to the low thermal inertia of the test section and small steps in the setpoints. Between different setpoints of the flow rate, there was a stabilization time of $10 \mathrm{~min}$. Altogether, one combination of channel height and inlet temperature measurement lasted for around $13 \mathrm{~h}$.

\section{MEASUREMENT ANALYSIS}

\section{Performance parameters}

The data resulting from the measurements are analyzed based on two important performance parameters: the thermal resistance due to convection at the baseplate and the pumping power necessary to overcome the pressure drop in the test section. The thermal resistance is defined as the temperature difference between baseplate wall $T_{w, a v g}$ and fluid inlet $T_{f, \text { in }}$ divided by the heat $Q_{e}$. The heating power can be determined based on the measurements of the current $I_{e}$ and voltage $V_{e}$ : $Q_{e}=I_{e} \times V_{e}$.

$$
R=\frac{T_{w, \text { avg }}-T_{f, \text { in }}}{Q_{e}}
$$

Based on the five thermocouple measurements in the grooves of the baseplate $\left(T_{T C 1} \rightarrow T_{T C 5}\right)$, the wall temperature can be approximated by subtracting the temperature drop due to conduction through the baseplate, from the average value of the thermocouple measurements:

$$
T_{w, \text { avg }}=\frac{\sum_{i=1}^{5} T_{T C_{i}}}{5}-\frac{Q_{e} \Delta x}{k_{A l} A_{h t}}
$$

With $\Delta x=3.25 \mathrm{~mm}$ the distance from the center of the groove until the wall, $k_{A l}$ the thermal conductivity of the aluminum baseplate and $A_{h t}=50 \times 108 \mathrm{~mm}^{2}$ the heat transfer surface.

The pumping power is the product of the flow rate and pressure drop over the test section, caused by frictional losses:

$$
P_{p}=\dot{V} \Delta p
$$

The flow rate $\dot{V}$ is measured by the ultrasonic flow meter and the pressure drop over the test section can be determined by subtracting the hydrostatic pressure term resulting from the increase in height, from the measured pressure difference $\Delta p_{\text {meas }}$ :

$$
\Delta p=\Delta p_{\text {meas }}-\rho g \Delta x
$$

With $\rho$ the fluid density, $g$ the gravitational constant and $\Delta x=$ $0.1 \mathrm{~m}$ the difference in height between the two pressure taps.

\section{Error analysis}

Firstly, the uncertainty of the measured values should be determined, which will then be used to do an analysis of the propagation of the measurement errors. The values used in the measurement analysis are an average of the 300 measurement done during steady-state. The absolute uncertainty $\delta_{a b s}$ on these values consists of a systematic uncertainty $\delta_{\text {sys }}$, caused by the measurement equipment and a random uncertainty $\delta_{\text {rand }}$, which is statistical and caused by variations in the different measurement values during the steady-state period. The systematic uncertainties can be found in Table 1 and the random uncertainties are approximated as the standard deviation $\sigma_{x}$ during the measurement period:

$$
\sigma_{x}=\sqrt{\frac{1}{N-1} \sum\left(x_{m e a s, i}-x_{a v g}\right)^{2}}
$$

With $N$ the amount of measurements, $x_{\text {meas }, i}$ measurement number $i$ and $x_{\text {avg }}$ the average measured value.

The absolute uncertainty is then calculated by the equation below. The random uncertainty is generally smaller than the absolute uncertainty, such that the absolute uncertainty is mostly caused by the uncertainty of the measurement equipment.

$$
\delta_{a b s}=\sqrt{\delta_{s y s}^{2}+\delta_{\text {rand }}^{2}}
$$

The uncertainty on the performance parameters, which are the thermal resistance and pumping power, can now be determined with the propagation of errors:

$$
\begin{gathered}
\delta R=\frac{1}{V I} \sqrt{\sum_{i=1}^{5} \frac{\delta T_{T C_{i}}^{2}}{25}+\delta T_{\text {in }}^{2}+\left(\sum_{i=1}^{5} \frac{T_{T C_{i}}}{5}-T_{i n}\right)^{2}\left(\frac{\delta V^{2}}{V^{2}}+\frac{\delta I^{2}}{I^{2}}\right)} \\
\delta P_{p}=\sqrt{\left(\delta \dot{V}\left(\Delta p_{\text {meas }}-\rho g \Delta x\right)\right)^{2}+(\delta \Delta p \dot{V})^{2}+(\delta \Delta x \rho g \dot{V})^{2}}
\end{gathered}
$$

For all the measurements it was checked whether the heat balance was closed, which means that the electrical power $Q_{e}$ going in is equal to thermal power $Q_{t h}=\dot{V} \rho c_{p}\left(T_{\text {out }}-T_{\text {in }}\right)$ coming out. However, it was not possible to do it properly for all the measurements. The reason is the relatively high uncertainty on the thermal power measurement, defined by:

$$
\delta Q_{t h}=\sqrt{\left(\delta \dot{V} \rho c_{p}\left(T_{\text {out }}-T_{\text {in }}\right)\right)^{2}+\left(\dot{V} \rho c_{p} \delta T_{\text {out }}\right)^{2}+\left(\dot{V} \rho c_{p} \delta T_{\text {in }}\right)^{2}}
$$

Because of the high flow rate, the fluid is heated by less than $1.76^{\circ} \mathrm{C}$ at maximum, and knowing that the uncertainty on the measured temperatures is more than $0.15^{\circ} \mathrm{C}$, this will result in an unreliable thermal power measurement in most of the cases. In the best circumstances, meaning the highest power and lowest flow rate, the relative error is minimum $15.7 \%$. In Figure 5 a comparison is shown between the electrical and thermal power of the lowest flow rate for each channel type at $20^{\circ} \mathrm{C}$. The black line represents the ideal case, where the heat balance is closed completely. Further in the analysis, the electrical power will be used because of the low uncertainty, which is $2.1 \%$ at maximum.

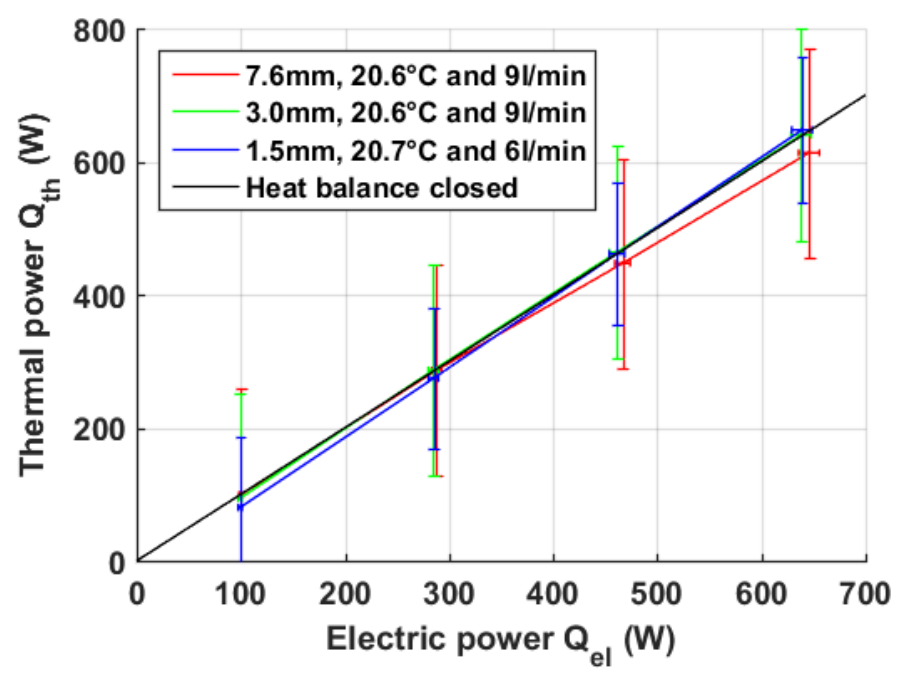

Figure 5: Closing of the heat balance. 

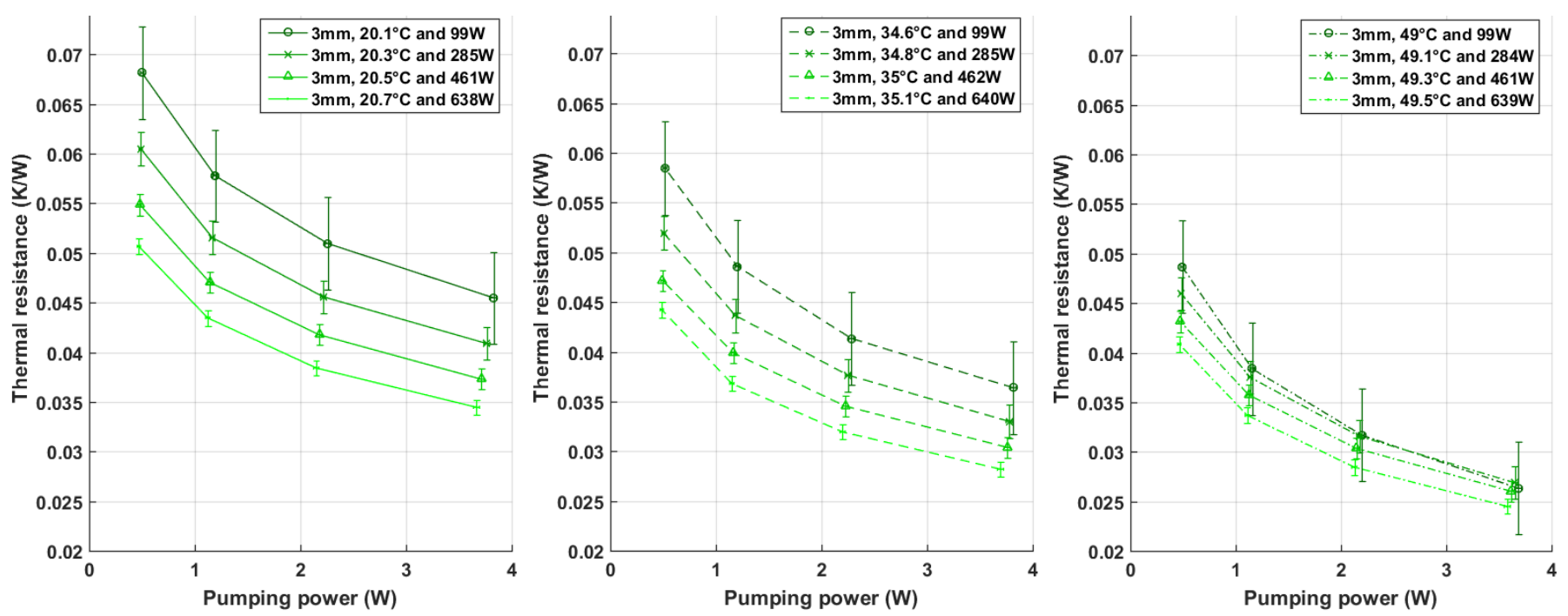

Figure 6: Influence of heating power on thermal resistance and pumping power for the $3 \mathrm{~mm}$ channel and $20^{\circ} \mathrm{C}$ (left), $35^{\circ} \mathrm{C}$ (middle) and $50^{\circ} \mathrm{C}($ right).

\section{MEASUREMENT RESULTS}

In the analysis that will follow, the pumping power is plotted on the $\mathrm{x}$-axis and the thermal resistance on the y-axis. The uncertainty as determined in the previous paragraphs is shown on the figure with error bars. The best performing configuration is the one with a low pumping power and low thermal resistance, which means close to the origin of the Figures 6-8.

\section{Influence of heating power}

The influence of the heating power on the thermal resistance and pumping is shown in Figure 6. The results for the $7.6 \mathrm{~mm}$ and $1.5 \mathrm{~mm}$ channels are similar. With an increasing heating power, the thermal resistance from wall to fluid inlet temperature decreases and the pumping power also slightly decreases. The relative decrease in thermal resistance and pumping power for a heating power from $100 \mathrm{~W}$ to $640 \mathrm{~W}$ are calculated for each inlet temperature and flow rate of the fluid, based on $\Delta \mathrm{R}=\left(\mathrm{R}_{640 \mathrm{~W}}-\mathrm{R}_{100 \mathrm{w}}\right) / \mathrm{R}_{100 \mathrm{w}}$ and $\Delta \mathrm{P}_{\mathrm{p}}=\left(\mathrm{P}_{\mathrm{p}, 640 \mathrm{~W}^{-}}\right.$

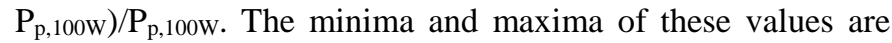
shown in Table 3 for each channel height.

Table 3: Min and max relative decrease in thermal resistance and pumping power for a heating power from $100 \mathrm{~W}$ to $640 \mathrm{~W}$

\begin{tabular}{|l|c|c|c|c|}
\hline $\mathbf{h}$ & $\boldsymbol{\Delta R}_{\min }$ & $\boldsymbol{\Delta R}_{\max }$ & $\boldsymbol{\Delta P}_{\boldsymbol{p}, \min }$ & $\boldsymbol{\Delta P}_{\boldsymbol{p}, \max }$ \\
\hline $7.6 \mathrm{~mm}$ & $-13 \%$ & $-27 \%$ & $-2.0 \%$ & $-4.8 \%$ \\
\hline $3.0 \mathrm{~mm}$ & $-7.0 \%$ & $-26 \%$ & $-2.9 \%$ & $-6.0 \%$ \\
\hline $1.5 \mathrm{~mm}$ & $-14 \%$ & $-22 \%$ & $-6.7 \%$ & $-21 \%$ \\
\hline
\end{tabular}

This decrease in thermal resistance and pumping power is a result of the higher wall temperature with higher heating power, causing a lower viscosity in the boundary layer near to the wall compared to the bulk viscosity. This effect is becomes important for viscous fluids and high temperature differences between wall and fluid [8] and was first investigated by Sieder and Tate [9]. The lower viscosity at the wall enhances the heat transfer and results in a lower thermal resistance. It also causes a decrease in friction between fluid and wall, resulting in a slightly lower pumping power. In scientific literature, a correction factor based on the ratio of the bulk viscosity $\mu_{b}$ to the wall viscosity $\mu_{w}$ is added to the correlations of the Nusselt number and friction factor, to take into account this effect [9]. The ratio of $\mu_{b} / \mu_{w}$ for the investigated temperature differences between wall and fluid is shown in Figure 7. From this figure, it is also clear that the influence of the heating power is less pronounced at higher inlet temperatures than lower temperatures. The uncertainty on the thermal resistance also decreases significantly with increasing heating power. Therefore, only the results at the highest heating power will be shown further in the analysis.

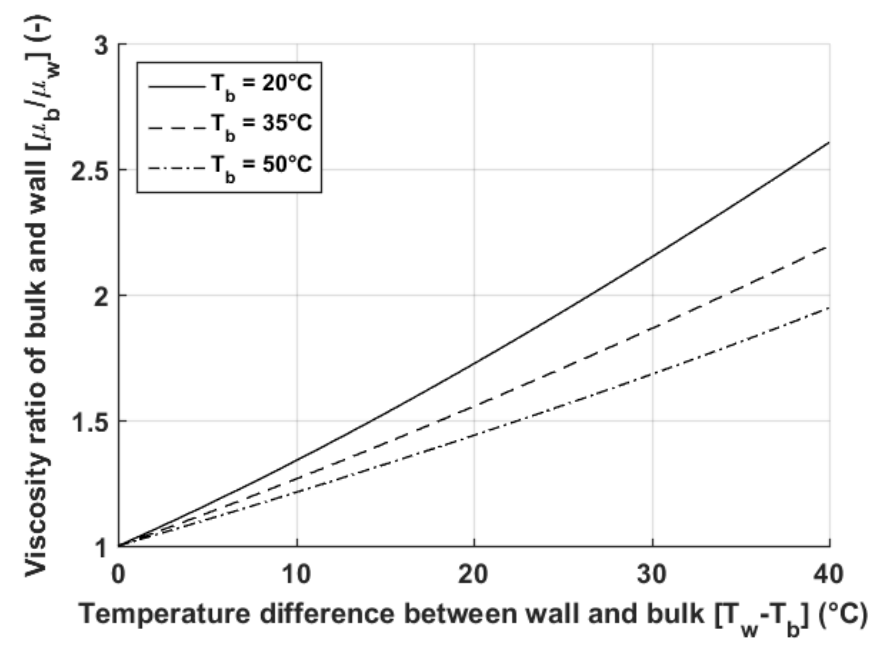

Figure 7: Viscosity ratio between bulk and wall for the investigated temperatures.

\section{Influence of inlet temperature}

In Figure 8 the effect of an increasing inlet temperature on the thermal resistance and pumping power is shown. The two performance parameters both decrease, which has the same cause as mentioned in the previous paragraph. With a higher fluid temperature, the viscosity of the water-glycol mixture decreases, enhancing the heat transfer and lowering the pumping power.

\section{Influence of channel height}

Finally, we can also study the influence of the channel height on the thermo-hydraulic performance. In Figure 9 a 
comparison is shown of the three channel heights for the three different inlet temperatures at the highest heating power. As shown in the figure, the performance of the three channel heights is quite similar. There is no clear difference between the $7.6 \mathrm{~mm}$ and $1.5 \mathrm{~mm}$ channel as it is within the measurement uncertainty. The $3.0 \mathrm{~mm}$ channel performs slightly better than the other two channel heights (curve closest to the origin). The average difference in thermal resistance for a fixed pumping power with the other two channels is around $-7.5 \%$ for an inlet temperature of $20^{\circ} \mathrm{C},-5.5 \%$ for an inlet temperature of $35^{\circ} \mathrm{C}$ and $-4.3 \%$ for an inlet temperature of $50^{\circ} \mathrm{C}$.

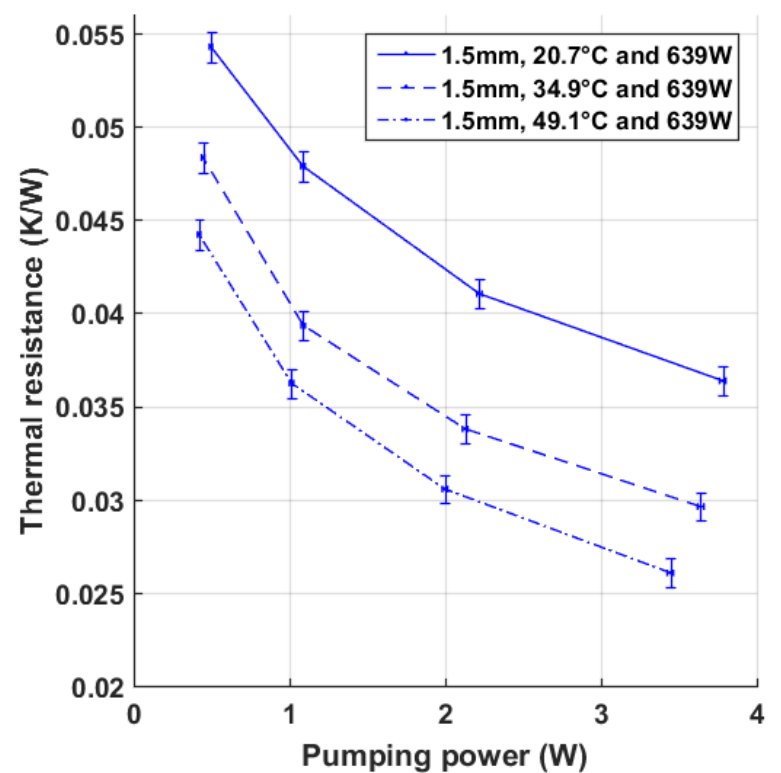

Figure 8: Influence of inlet temperature for the $1.5 \mathrm{~mm}$ channel and maximum applied heating power of $639 \mathrm{~W}$.

\section{CONVECTIVE HEAT TRANSFER ANALYSIS}

The heat transfer coefficient can also be analyzed in function of the Reynolds number. Therefore, several parameters will be defined here with their investigated ranges, which can be calculated from the results for each steady-state measurement point:
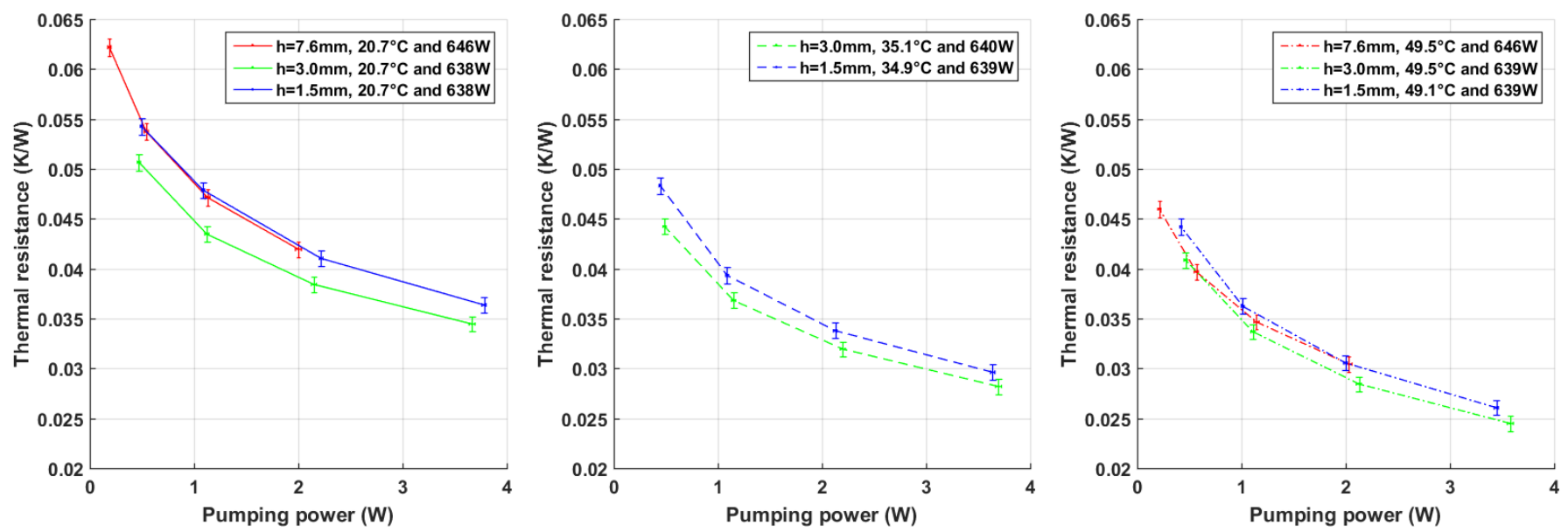

Table 4: Parameter definition and range.

\begin{tabular}{|l|c|}
\hline Number & Range \\
\hline Hydraulic diameter $D_{h}=\frac{2(h w)}{h+w}$ & $\begin{array}{c}13.1 ; 5.6 ; \text { and } \\
2.9 \mathrm{~mm}\end{array}$ \\
\hline Reynolds number $\operatorname{Re}=\frac{\dot{V} D_{h}}{A_{t f} v}$ & $1553 \rightarrow 8975$ \\
\hline Prandtl number $P r=\frac{{ }^{c} v \rho}{k}$ & $10.7 \rightarrow 23.5$ \\
\hline Nusselt number $\mathrm{Nu}=\frac{D_{h}}{k} \frac{Q}{A_{h t}\left(T_{w}-T_{f, a v g}\right)}$ & $29.4 \rightarrow 704.6$. \\
\hline
\end{tabular}

With $w$ the width of the channel, $h$ the channel height, $A_{f}$ the flow area, $v, c_{p}, \rho$ and $k$ respectively the kinematic viscosity, heat capacity, density and thermal conductivity of the fluid and $T_{w}$ the average wall temperature.

The Reynolds number in the measurements ranges from 1553 to 8975 , which means that laminar ( $\operatorname{Re} \lesssim 2300$ ), turbulent $(10000 \lesssim \mathrm{Re})$, and transitional flow can occur. The axial length of the channels is relatively short compared to the hydraulic diameter of the channel. We can determine whether the developing effect of the flow will be significant, by calculating the hydraulic $L_{h y}$ and thermal $L_{t h}$ entrance lengths for each channel and flow (laminar and turbulent) [8]. In Table 5 the lengths are shown, where $L^{+}=L / D_{h} R e$ and $L^{*}=L / D_{h} \operatorname{RePr}$ are the dimensionless axial lengths of the channel.

Table 5: Overview of the hydraulic and thermal entrance lengths (all values in table multiplied by factor $10^{3}$ ).

\begin{tabular}{|c|c|c|c|c|c|c|}
\hline $\mathbf{h}$ & $\boldsymbol{L}^{+}$ & $\boldsymbol{L}^{*}$ & $\boldsymbol{L}_{\text {hy,lam }}^{+}$ & $\boldsymbol{L}_{\text {hy,turb }}^{+}$ & $\boldsymbol{L}_{\text {th }, \text { lam }}^{*}$ & $\boldsymbol{L}_{\text {th }, \text { turb }}^{+}$ \\
\hline $7.6 \mathrm{~mm}$ & $1.0 \rightarrow 4.0$ & $0.09 \rightarrow 0.18$ & 5.6 & $1.6 \rightarrow 4.5$ & 4.3 & $3.7 \rightarrow 14.6$ \\
\hline $3 \mathrm{~mm}$ & $2.1 \rightarrow 8.5$ & $0.19 \rightarrow 0.38$ & 5.6 & $1.5 \rightarrow 4.2$ & 4.3 & $3.3 \rightarrow 13.4$ \\
\hline $1.5 \mathrm{~mm}$ & $5.7 \rightarrow 24$ & $0.5 \rightarrow 1.1$ & 5.6 & $1.9 \rightarrow 5.5$ & 4.3 & $4.6 \rightarrow 19.3$ \\
\hline
\end{tabular}

The measurements of the $7.6 \mathrm{~mm}$ channel are completely situated in the developing flow region; thermally and hydraulically. In the laminar region, the measurements of the $3 \mathrm{~mm}$ and $1.5 \mathrm{~mm}$ channel are fully situated in the thermal developing flow region and partially in the hydraulic developing flow region. In the turbulent region, the 1.5 and $3 \mathrm{~mm}$ channel are completely situated in the thermal developing region and partially in the hydraulic developing flow region.

Figure 9: Influence of channel height on thermal resistance and pumping power for $Q_{\text {max }}$ and $20^{\circ} \mathrm{C}$ (left), $35^{\circ} \mathrm{C}$ (middle) and $50^{\circ} \mathrm{C}($ right) 

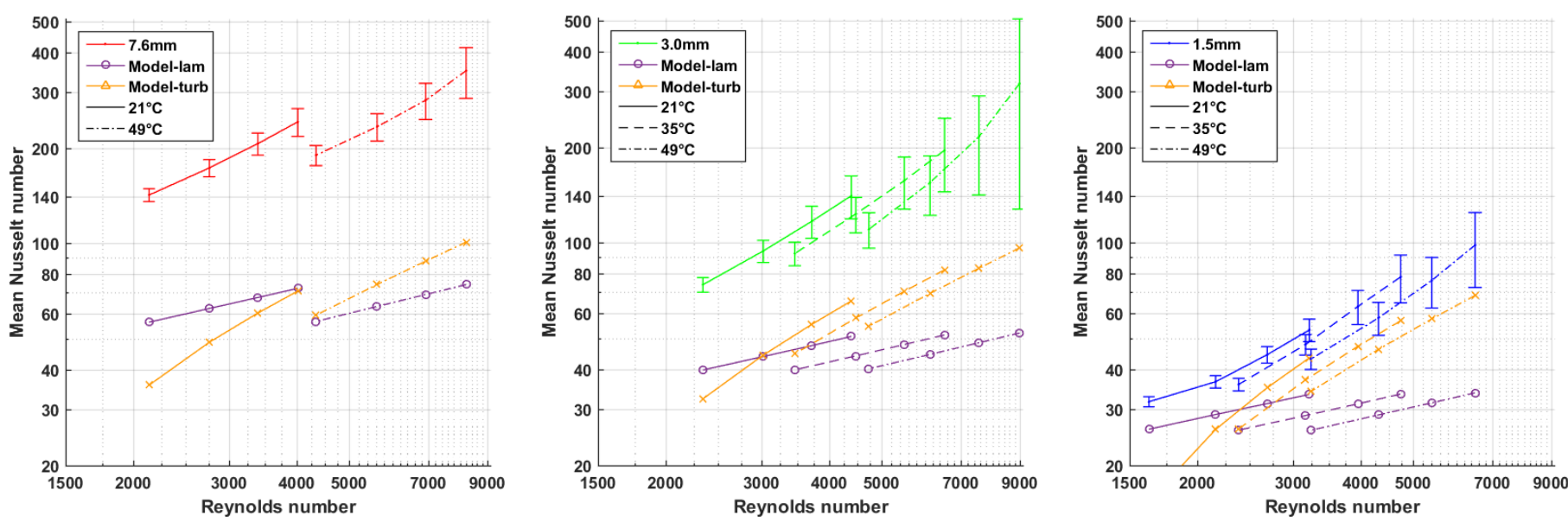

Figure 10: Nusselt number evaluated in function of Reynolds number, together with correlations for laminar and turbulent developing flows for a channel height of $7.8 \mathrm{~mm}$ (left), $3.0 \mathrm{~mm}$ (middle) and $1.5 \mathrm{~mm}$ (right).

The Nusselt number as a function of Reynolds number for the datapoints with the highest power are shown in Figure 10 with logarithmic scales. Further, two Nusselt number correlations from literature are included in the figure. In the laminar region, the correlation of Shah and London [10] is used, for simultaneously developing flow with the uniform heat flux boundary condition, which is the best approximation. The correlation is given by:

$$
N u_{m, l a m}=0.775(f R e)^{1 / 3}\left(\frac{\mu}{\mu_{w}}\right)^{0.14}\left(L^{*}\right)^{-1 / 3}
$$

With $f$ the friction factor for fully developed flow.

In the turbulent region, the correlation of Gnielinski [8] is used, with a correction of Al-Alarbi et al. for simultaneously developing flow [11]:

$$
\begin{gathered}
N u_{m, t u r b}=\frac{\frac{f_{\infty}}{8}(\operatorname{Re}-1000) P r}{1+12.7 \sqrt{f_{\infty} / 8}\left(\operatorname{Pr}^{2 / 3}-1\right)}\left(\frac{\mu}{\mu_{w}}\right)^{0.14}\left(1+\frac{C}{L / D_{h}}\right) \\
\text { With } f_{\infty}=\left(1.8 \log _{10} R e-1.5\right)^{-2} \text { and } C=\frac{\left(L / D_{h}\right)^{0.1}}{\operatorname{Pr}^{1 / 6}}\left(0.68+\frac{3000}{R e^{0.81}}\right)
\end{gathered}
$$

The correlations do not show a good agreement with the experiments and are mostly underestimating the Nusselt numbers. The laminar correlation underestimates all the Nusselt numbers, and predicts a different slope between Reynolds and Nusselt number than the experiments, except for the measurement between the two lowest Reynolds numbers 1629 and 2162 in case of the $1.5 \mathrm{~mm}$ channel and $20^{\circ} \mathrm{C}$ inlet temperature. This might indicate that somewhere between these two Reynolds numbers, the laminar flow region ends and the critical Reynolds number is reached.

The correlation for turbulent flow looks more promising for predicting the Nusselt numbers, because the prediction of the slope between the Reynolds and Nusselt number is closer to the one of the experiments. The correlation is relatively close to the heat transfer in the experiments for the $1.5 \mathrm{~mm}$ channel and underestimates the heat transfer for the other two channel heights (more for $7.6 \mathrm{~mm}$ channel than for the $3 \mathrm{~mm}$ channel).

The deviations between correlations and experiments can possibly be explained by the specific inlet and outlet geometry. In both the inlet and outlet the flow is deflected $90^{\circ}$ two times, there is a contraction/expansion, and depending on the channel height there is an additional expansion or contraction. These can initiate vortices in the flow, which can trigger the flow to have a turbulent behavior. As a result, the Nusselt number correlates to the Reynolds number with more turbulent behavior and the transition between laminar and turbulent flow could occur at a lower Reynolds number than expected (2300 for flow in circular channels).

The higher deviation between correlations and measurements for a bigger channel height, indicate that the inlet effect is more pronounced in case of a higher channel than a small channel. This could also be strengthened by the analysis of the entrance lengths, which are shorter with decreasing channel height. The inlet effect will therefore also be dissipated quicker in the flow for smaller channels than bigger channels. Further research into these phenomena is planned to investigate the differences between the correlations and the experiments.

\section{CONCLUSION}

Several experiments have been performed to investigate the thermo-hydraulic performance of direct contact baseplate cooling which can be used for the cooling of the power electronics in electric vehicles. In these experiments, the influence of the fluid temperature, heating power and three channel heights on the thermal resistance and pumping power were studied. A higher heating power and/or fluid inlet temperature results in a lower thermal resistance and pumping power, as a result of the lower viscosity of the fluid (at the wall). The performance of the $1.5 \mathrm{~mm}$ and $7.6 \mathrm{~mm}$ channel was found to be quite similar, while the $3 \mathrm{~mm}$ channel results on average in a 5.8\% lower thermal resistance compared to the other two channel heights. Compared to the heating power and inlet temperature, the channel height has a minor influence on the performance.

The convective heat transfer in the channel was also investigated more in depth. Based on an analysis of the hydraulic and thermal entrance lengths, it could be concluded that the flow in the channel is strongly developing. Two specific correlations for simultaneously developing flow in the laminar and turbulent flow region were compared to the results of the experiments, but the agreement was poor. However, the comparison shows that the flow in the channel has a similar behavior to turbulent flow and also that the transition from laminar to turbulent might occur earlier than expected. This is probably caused by the specific inlet and outlet of the channel. 
The influence of the inlet effect on the heat transfer is more pronounced for a bigger channel height than smaller channel heights. A more in depth investigation is necessary to explain these findings and to find an appropriate method to correlate the results. These correlations could then be used to design the direct contact baseplate cooling properly, with other fluids and channel dimensions as well. Furthermore, the results with respect to other investigated heat sinks (pin fin base plate; turbulator; cold plate cooling) and a variation in the used fluid will be demonstrated in a separate paper.

\section{Acknowledgments}

This research was supported by Flanders Make, the strategic research centre for the manufacturing industry, and the HERMESFONDS in the framework of the Hipercool project (HBC.2016.0463).

\section{References}

[1] K. Rajashekara, "Present Status and Future Trends in Electric Vehicle Propulsion Technologies," IEEE Journal of Emerging and Selected Topics in Power Electronics, vol. 1, no. 1, pp. 3-10, 2013.

[2] S. S. Anandan and V. Ramalingam, "Thermal management of electronics: A review of literature," Thermal science, vol. 12, no. 2, pp. 5-26, 2008.

[3] J. Nonneman, et al., "Model-Based Comparison of Thermo-Hydraulic Performance of Various Cooling Methods for Power Electronics of Electric Vehicles," in 2018 17th IEEE Intersociety Conference on Thermal and Thermomechanical Phenomena in Electronic Systems (ITherm), 2018, pp. 398-409.
[4] K. Olesen, et al., "Shower Power: New Cooling Concept for Automotive Applications," in Proceedings of the Automotive Power Electronics Conference, Paris, France, 2006, pp. 1-9.

[5] T. Hitachi, et al., "Direct Liquid Cooling IGBT Module for Automotive Applications," Power Semiconductor Contributing in Energy and Environment Region, vol. 58, no. 2, p. 55, 2012.

[6] S. S. Kang, "Advanced Cooling for Power Electronics," in 2012 7th International Conference on Integrated Power Electronics Systems (CIPS), 2012, pp. 1-8.

[7] I. T'Jollyn, et al., "Experimental study of design parameter influence on thermal and hydraulic performance of cold plates," in Thermal and Thermomechanical Phenomena in Electronic Systems (ITherm), 2017 16th IEEE Intersociety Conference on, 2017, pp. 551-557.

[8] R. K. Shah and D. P. Sekulic, Fundamentals of heat exchanger design: John Wiley \& Sons, 2003.

[9] E. N. Sieder and G. E. Tate, "Heat transfer and pressure drop of liquids in tubes," Industrial \& Engineering Chemistry, vol. 28, no. 12, pp. 14291435, 1936.

[10] R. K. Shah and A. L. London, Laminar flow forced convection in ducts: a source book for compact heat exchanger analytical data: Academic press, 2014.

[11] M. Al-Arabi, "Turbulent Heat Transfer in the Entrance Region of a Tube," Heat Transfer Engineering, vol. 3, no. 3-4, pp. 76-83, 1982/01/01 1982. 